\title{
Implication of Acute, Sub-chronic and Chronic Exposure to Different Pesticides via Inhalation on Male Wistar Rats
}

\author{
Oluwatoyin Taiwo Adeoti, Donatus Chuka Belonwu, Mathew Owhonda Wegwu, \\ Justice Obinna Osuoha*
}

Department of Biochemistry, University of Port Harcourt, Nigeria

Copyright $\subseteq 2017$ by authors, all rights reserved. Authors agree that this article remains permanently open access under the terms of the Creative Commons Attribution License 4.0 International License

\begin{abstract}
This study was carried out to investigate the combined toxicological effects of ten pesticides: Paraquat, Termicot (Chlorpyrifos), Sniper (Dichlorvos (Ddvp), Best (Cypermethrin), Delta Force (Deltamethrin), Vitoate 40 EC (Dimethoate), Force Up (Glyphosate), Attacke and Karto (Lambda Cyhalothrin) on some selected hematological and biochemical profile of male Wistar rats. Thirty six male Wistar rats weighing 152-198g were divided into three groups on weight basis. Groups' 1 and 2 containing 12 rats each were exposed to the pesticides by inhalation for 8 hours daily while the rats in group 3 received normal feed and water and constituted the male control for comparison. The Wistar rats were used to simulate the interminate exposure of farmers and retailers who use and sell these pesticides regularly. In comparison to male control animals alanine aminotransferase (ALT), aspartate aminotransferase (AST) and alkaline phosphatase (ALP) levels of the male rats exposed to these pesticides fumes increased significantly $(p<0.05)$. The hematological parameters revealed an insignificant decrease in red blood cell count (RBC) indices after 2 weeks and a further insignificant decrease in $\mathrm{RBC}$ after 4 weeks in the male rats, hemoglobin (HB) and packed cell volume (PCV) levels also decreased significantly $(\mathrm{P}<0.05)$ after 2 weeks with more significant decrease after 4 weeks in the male rats when compared to the male control respectively. While white blood cell (WBC), neutrophils (N) and lymphocytes (L) increased insignificantly $(\mathrm{P}>0.05)$ after $2^{\text {nd }}$ and $4^{\text {th }}$ week in the male rats respectively. However, there was no significant difference in the levels of urea and creatinine as well as other serum electrolytes of the male rats after the $2^{\text {nd }}$ and $4^{\text {th }}$ week as compared to the male control. The results suggest that exposure to pesticides by inhalation leads to hepatotoxicity and anemia and continuous exposure to pesticides fumes may be toxic and capable of causing multiple organ toxicity, if results of this present
\end{abstract}

study can be extrapolated to man.

Keywords Pesticides, Hepatotoxicity, Toxicology, Oxidative Stress, Hematology, Nephrotoxicity

\section{Introduction}

In recent times, upon cognizance of the severe effects associated with the use of pesticides on humans, its usage is still on the increase in Nigeria and other developing nations in Africa ${ }^{(1)}$. Pesticides, developed after the Second World War due to the ubiquity of plant diseases to manage and/or control pest in our society had been widely adopted for industrial, domestic and agricultural purposes and had become a widespread and essential need of human life style today in Nigeria. The prevalence of pesticide toxicity in Nigeria and other developing countries may not be unconnected to a poor or perhaps missing legislative structure and the misuse of the toxic pesticides generally ${ }^{(2)}$. It is imperative to evaluate the potential undesirable effects these pesticides may portent on the retailers who sell them, agricultural workers' and humans health and wellbeing due to the myriad number of pesticides used in agriculture today ${ }^{(3)}$.

Humans are exposed to pesticides basically by three ways namely; dermal, oral and inhalation ${ }^{(4)}$, and much emphasis has been made on the oral means of exposure and some reports had implicated the oral means to cause multiple organ toxicity ${ }^{(5)}$. Many scientists had focused their research on agricultural workers' health and third party consumers but there has been neglect on the retailers that sell these pesticides to the workers, information on their health status is scanty considering the fact that they are unavoidably exposed to the fumes of these pesticides 
on daily basis on a poor ventilated shop. The latter route of exposure by inhalation is very common in Nigeria because the retailers who sell them and some of the farmers who spray these pesticides are not properly educated on the safety protocols involved in pesticides. More so, incessant inhalation of pesticides is very perilous because it is swiftly absorbed into the blood stream by the lungs where toxicity is ranged from moderate to hazardous ${ }^{(6)}$. Reproductive toxicity is a topic of increasing interest in consideration of environmental health hazards (7). According to (3) assessment of the potential influences of pesticides on agricultural workers' health is sacrosanct considering the huge volume of pesticides used in the sector. Many clinical trials ${ }^{(8)}$ have demonstrated the capacity of pesticides to interfere with reproductive and endocrine system.

Owing to the fact that exposure to pesticides has become a public health challenge and that there is a definite alteration on reproduction as a consequence of pesticide exposure, the following study was planned to observe the toxic combined effect induced by some selected pesticides on the reproductive hormone profile, haematological indices as well as on some biochemical profile of male Wistar rats. In order to simulate a real lifetime event, based on availability, ten pesticides Paraquat, Termicot (Chlorpyrifos), Sniper (Dichlorvos (Ddvp), Best (Cypermethrin), Delta Force (Deltamethrin), Vitoate 40 EC (Dimethoate), Force Up (Glyphosate), Attacke and Karto (Lambda Cyhalothrin) commonly sold and used in Nigeria were chosen to evaluate the combined toxicological effects caused by inhalation of these compounds.

\section{Materials and Methods}

\subsection{Pesticides}

The pesticides used Paraquat, Termicot (Chlorpyrifos), Sniper (Dichlorvos (Ddvp), Best (Cypermethrin), Delta Force (Deltamethrin), Vitoate 40 EC (Dimethoate), Force Up (Glyphosate), Attacke and Karto (Lambda Cyhalothrin) were obtained directly from the sellers at Ariaria international market, Aba, Abia State, Nigeria.

\subsection{Experimental Animals}

Thirty six male wistar rats weighing $152-198 \mathrm{~g}$ were procured from the animal house at University of Port Harcourt. Three equal groups were created from these animals, caged with standardization of the environmental conditions for the minimization of fallacies.They were acclimatized for two weeks on guinea mash obtained from Flour Mills in Port Harcourt, Nigeria.

On weight basis, the rats were grouped into three groups: one control group and two test groups $(1,2)$, each group containing 12 rats were used for inhalation treatments and were exposed to the pesticides by inhalation for 8 hours daily.

Group 1: male rats weighing $152-158 \mathrm{~g}$ exposed to the pesticides by inhalation for 8 hours daily.

Group 2: male rats weighing $180-186 \mathrm{~g}$ exposed to the pesticides by inhalation for 8 hours daily.

Male control: was kept as male control without exposure.

Locally made inhalation chamber was used. The test animals were grouped into two groups on weight basis in order to simulate a real life time event where persons of different bodyweights stay in the shops and to determine if there is a relationship between bodyweight and rate of metabolism of xenobiotics in vivo. The rats that were not exposed constituted the male control for comparison.

\subsection{Collection of Blood Samples}

After every week, three rats were sacrificed from their cage and their blood samples were collected with EDTA bottles. Centrifugation of the blood was performed at 4000 rpm for ten minutes, using a refrigerated centrifuge, to obtain plasma and then analyzed in the laboratory to assess levels of haematological and biochemical indices.

\subsection{Determination of Hematological Indices}

The concentration of red blood cell, hemoglobin, packed cell volume, white blood cell, neutrophils and lymphocytes were analyzed using BC 5300 Mindray Hematology Auto Analyzer.

\subsection{Determination of Biochemical Profile}

The tissue activities of AST, ALT, ALP, Urea, Creatinine and plasma electrolytes were determined enzymatically using Randox Kits. All samples were analysed in triplicates.

\subsection{Determination of Reproductive Profile}

The reproductive profile hormones were assayed using enzyme linked immunosorbent assay (ELISA) test kit.

\subsection{Statistical Analysis}

For the obtained triplicate data, SPSS Software 20 was used for the statistical analysis.

\section{Results}

The result of the effect of chronic exposure to pesticides on haematological indices of male rats is presented in Figures 1 and 2. After 2 weeks, the decrease was insignificant in the $\mathrm{Hb}$ level of the exposed animals in group $1(7.10 \pm 0.10)$ and group $2(7.03 \pm 0.15)$ when 
compared to the normal control $(9.70 \pm 1.00)$ but significant in the levels of PCV of group $1(21.33 \pm 2.30)$ and group 2 $(21.66 \pm 3.05)$ in comparison to the normal control group $(29.00 \pm 3.00)$ while decrease was insignificant in the levels of RBC of the group $1(2.56 \pm 0.40)$ and group 2 (2.73 \pm 0.20 ) when compared to the normal control group (3.70 \pm 0.50 ). Moreover, after 4 weeks a significant decrease was demonstrated in the $\mathrm{Hb}$ levels of group $1(3.83 \pm 0.15)$ and group $2(3.56 \pm 0.47)$ animals when compared to the control group $(10.00 \pm 1.00)$ and also in the levels of PCV of group $1(12.33 \pm 1.52)$ and group $2(11.66 \pm 1.52)$ compared to the normal control $(30.00 \pm 3.00)$. However, in comparison to the control group $(3.60 \pm 0.40)$ the levels of RBC decreased insignificantly in group $1(1.06 \pm 0.15)$ and group $2(0.96$ \pm 0.15 ). More so, as uncovered in (figure 2), in comparison to the male control group (4.10 \pm 0.00$)$ increase was significant in the levels of WBC of male rats in group 1 $(8.63 \pm 0.23)$ and group $2(9.13 \pm 0.49)$ after 4 weeks. Also, there was an insignificant increase in the levels Neutrophils of the male rats in group $1(34.00 \pm 2.00)$ and group $2(33.00$ $\pm 3.00)$ compared to the male control $(25.00 \pm 5.00)$ after 2 weeks and a further significant increase was observed in group $1(37.00 \pm 1.00)$ and group $2(37.00 \pm 0.00)$ compared to the male control $(24.00 \pm 1.00)$ after 4 weeks. Conversely, in comparison to the male control $(77.00 \pm 1.00)$ the levels of lymphocytes revealed an insignificant increase after four weeks in group $1(82.33 \pm 2.08)$ and group $2(83.0 \pm 0.00)$.

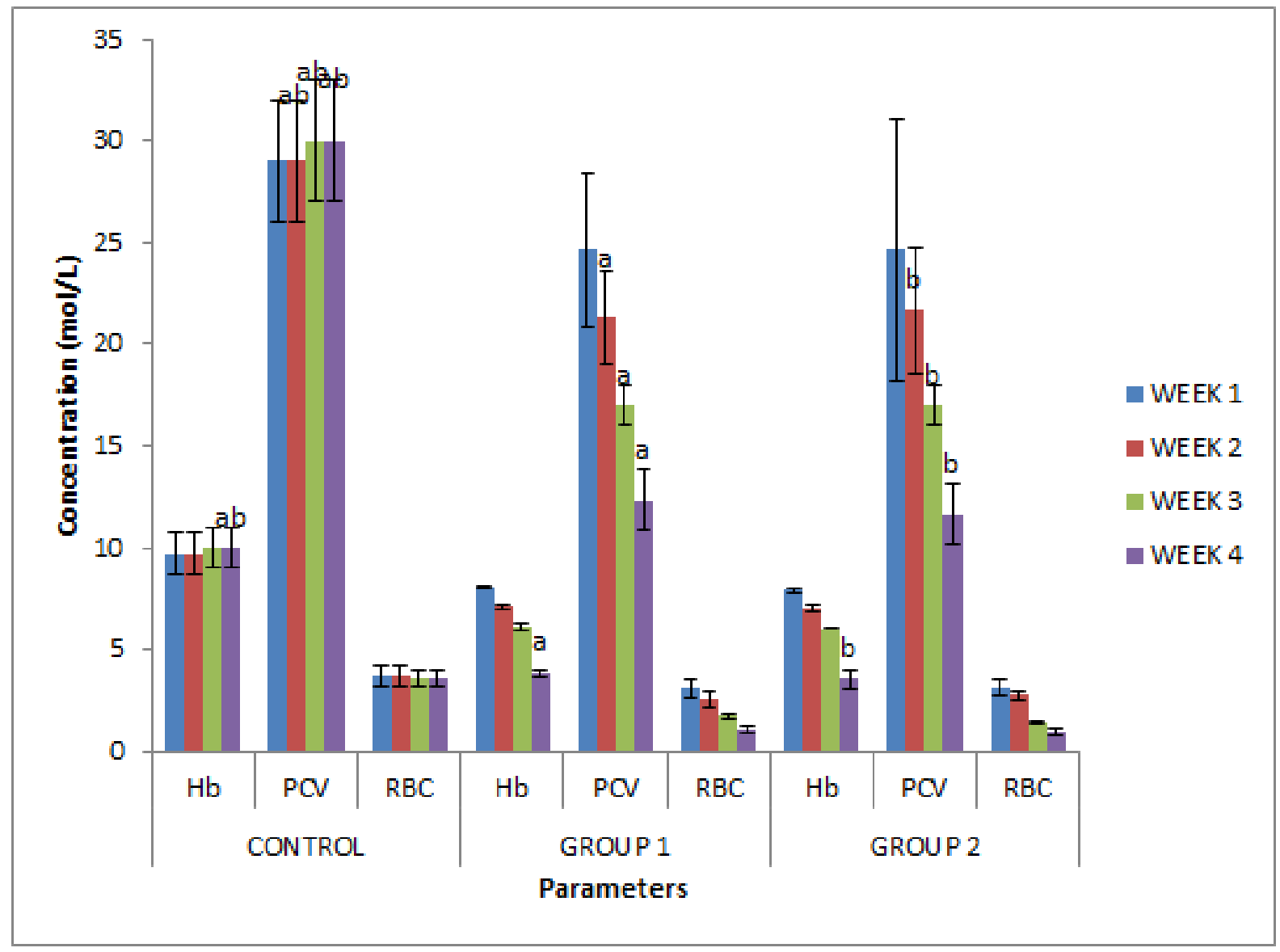

Data are mean \pm standard deviation of triplicate determinations. Superscripts $a, b$, indicate significant difference $(\mathrm{P}<0.05)$ when compared to the control group.

Superscript $\mathrm{A}^{(\mathrm{a})}$ denotes significant difference when the normal control group are compared with group 1.

Superscript $\mathrm{B}^{(\mathrm{b})}$ denotes significant difference when the normal control group is compared with group 2. Values without superscripts indicate no significant difference when the normal control is compared to group 1 and 2

Figure 1. Effects of chronic exposure to pesticides on haematological indices of male rats 


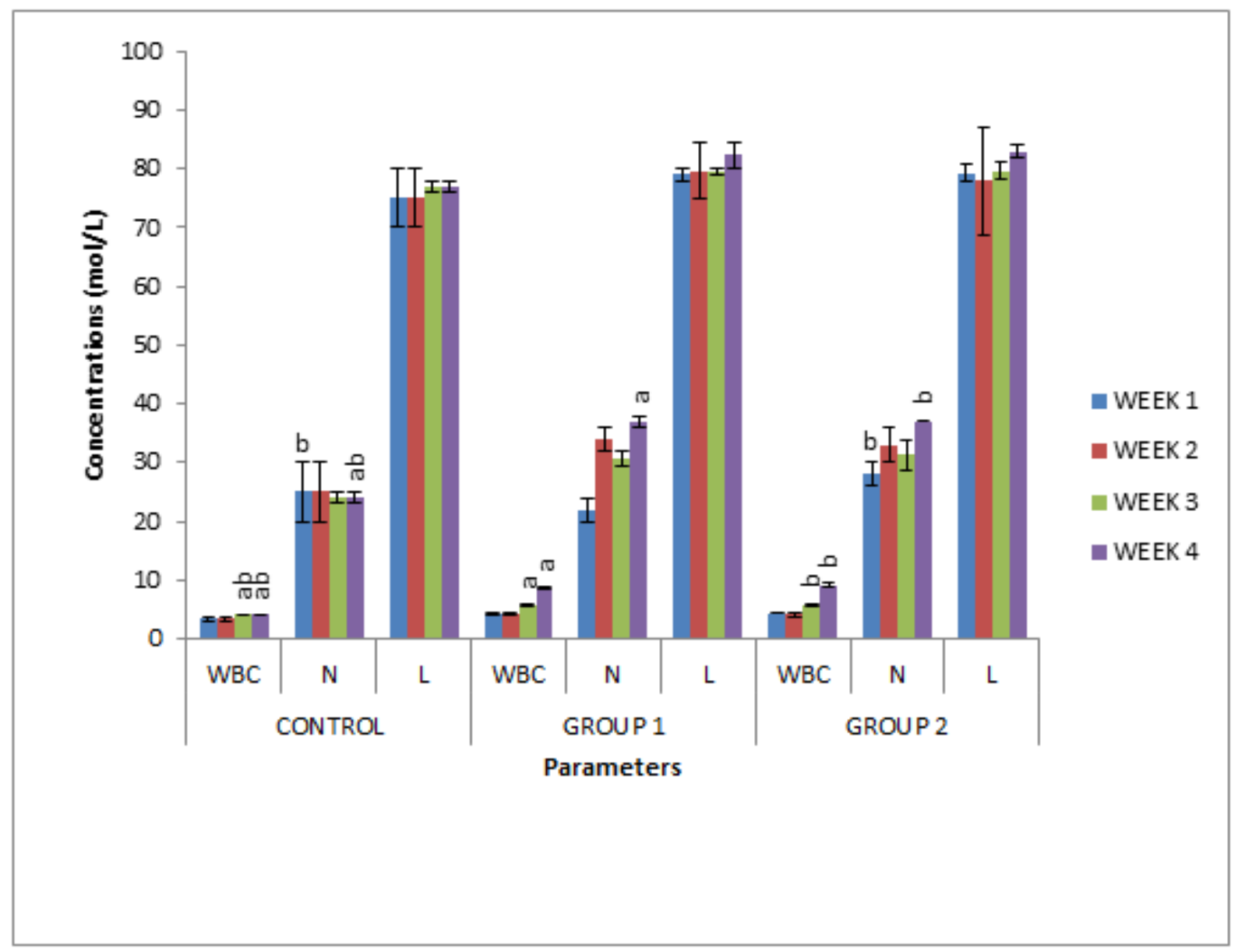

Data are mean \pm standard deviation of triplicate determinations. Superscripts $a, b$, indicate significant difference $(\mathrm{P}<0.05)$ when compared to the control group.

Superscript $\mathrm{A}^{(\mathrm{a})}$ denotes significant difference when the normal control group are compared with group 1.

Superscript $\mathrm{B}^{(\mathrm{b})}$ denotes significant difference when the normal control group is compared with group 2 . Values without superscripts indicate no significant difference when the normal control is compared to group 1 and 2

Figure 2. Effects of chronic exposure to pesticides on WBC, Neutrophil and Lymphocyte concentration of male rats

The effect of chronic exposure to pesticides on liver enzyme markers and total protein and albumin levels of male rats are presented in Figures 3 and 4 . There was a significant increase in the levels of AST of the exposed rats in group $1(169.0 \pm 5.0)$ and group $2(195.2 \pm 10.0)$ compared to the normal control $(125.0 \pm 12.0)$ after two weeks and a further significant elevation in the levels of AST in group $1(191.0 \pm 5.0)$ and group $2(217.0 \pm 10.0)$ compared to the normal control $(118.0 \pm 12.0)$ after four weeks. Similarly, in comparison to the normal control $(32.0 \pm 2.0)$ an insignificant increase was observed in the levels of ALT in group $1(71.0 \pm 7.0)$ while those in group 2 (76.0 \pm 2.0$)$ revealed a significant increase after two weeks, also, a significant increase was observed in group 1 (79.0 $\pm 7.0)$ and group $2(84.0 \pm 12.0)$ compared to the normal control after four weeks. Furthermore, ALP concentrations in the group $1(60.0 \pm 1.0)$ revealed an insignificant increase while those in group $2(79.0 \pm 1.0)$ revealed a significant increase when compared to the normal control $(40.0 \pm 1.0)$ after two weeks. However, a significant increase was observed in group $1(74.0 \pm 1.0)$ and group $2(93.0 \pm 1.0)$ in the levels of ALP when compared to the normal control $(34.0 \pm 2.0)$ respectively. There was a significant decrease in the levels of Total protein in the male rats after four weeks. 


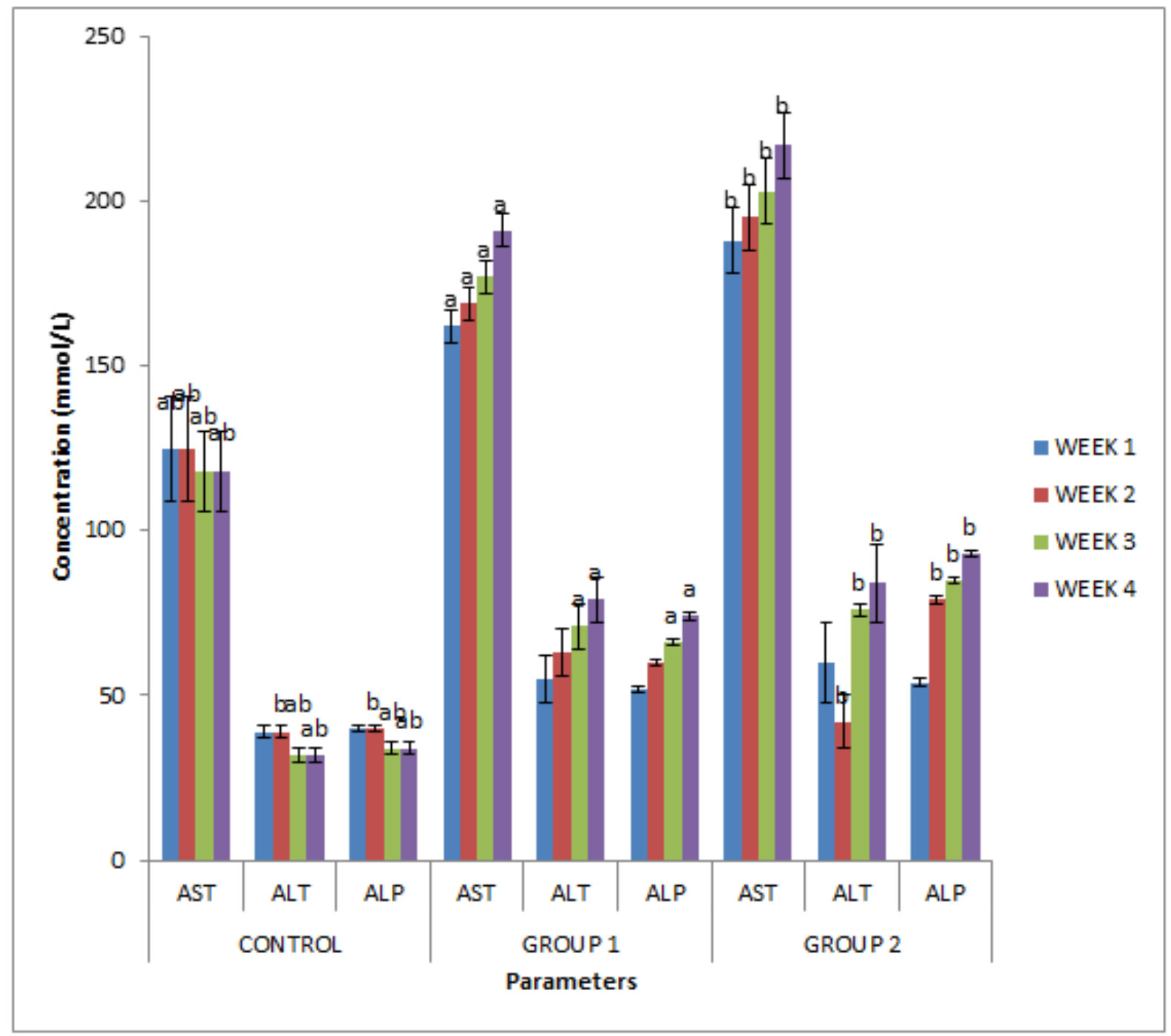

Data are mean \pm standard deviation of triplicate determinations. Superscripts $a, b$, indicate significant difference $(\mathrm{P}<0.05)$ when compared to the control group.

Superscript $\mathrm{A}^{(\mathrm{a})}$ denotes significant difference when the normal control group are compared with group 1.

Superscript $\mathrm{B}^{(\mathrm{b})}$ denotes significant difference when the normal control group is compared with group 2. Values without superscripts indicate no significant difference when the normal control is compared to group 1 and 2

Figure 3. Effects of chronic exposure to pesticides on liver enzyme markers of male rats 


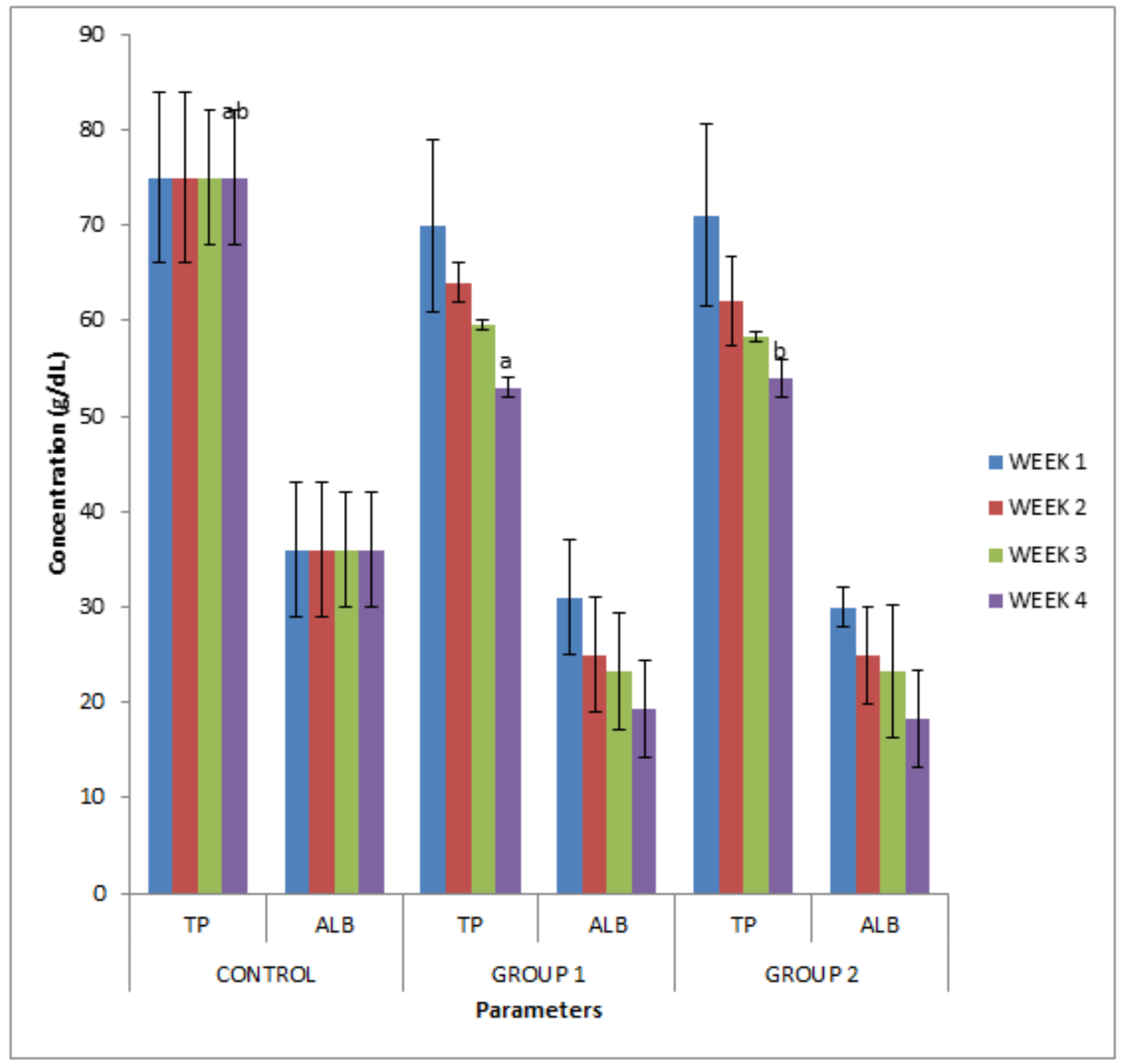

Data are mean \pm standard deviation of triplicate determinations. Superscripts $a, b$, indicate significant difference $(\mathrm{P}<0.05)$ when compared to the control group.

Superscript $\mathrm{A}^{(\mathrm{a})}$ denotes significant difference when the normal control group are compared with group 1.

Superscript $\mathrm{B}^{(\mathrm{b})}$ denotes significant difference when the normal control group is compared with group 2. Values without superscripts indicate no significant difference when the normal control is compared to group 1 and 2

Figure 4. Effects of chronic exposure to pesticides on total protein and albumin levels of male rats

The effects of chronic exposure to pesticides on some selected kidney markers of male rats are presented in Figures 5 and 6 . In comparison to the male control (47.0 \pm 3.0) the concentration of the plasma electrolyte NA

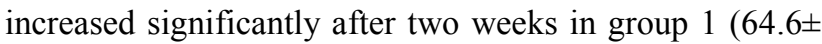
$4.0)$ and group $2(64.3 \pm 3.2)$ and also revealed a further significant increase in group $1(100.0 \pm 2.6)$ and group 2 $(99.6 \pm 7.23)$ compared to the male control $(53.0 \pm 7.0)$ after four weeks. While an increase that was insignificant was observed in the levels of $\mathrm{K}$ of the exposed rats in group 1 $(7.7 \pm 0.2)$ and group $2(7.7 \pm 0.4)$ compared to the male control $(5.5 \pm 0.05)$ after two weeks and a further insignificant decrease in group $1(17.6 \pm 0.5)$ and group 2 $(18.0 \pm 0.1)$ compared to male control $(5.3 \pm 0.1)$ after four weeks. Urea concentration revealed a decrease that was insignificant in group $1(9.6 \pm 0.1)$ and group $2(9.4 \pm 0.05)$ compared to the male control $(6.2 \pm 0.9)$ after 2 weeks and a further significant decrease in group $1(19.2 \pm 0.6)$ and group $2(19.1 \pm 0.3)$ in comparison to the male control (6.1 \pm 0.7 ) respectively after four weeks. More so, according to data in (figure 6), the creatinine concentration after 2 weeks revealed an insignificant increase in group $1(252.6 \pm 23.5)$ and group $2(252.3 \pm 23.5)$ compared to the male control group (249.0 \pm 23.0$)$ and a further insignificant increase after four weeks in group $1(278.6 \pm 5.5)$ and group 2 (279.3 \pm 3.5$)$ compared to the male control $(249.0 \pm 23.0)$ respectively. Also, in comparison to the male control (69.0 \pm 1.0$)$ the chloride ion levels increased insignificantly 
in group $1(75.0 \pm 0.01)$ and group $2(74.3 \pm 2.3)$ after two weeks and a further insignificant increase was observed after four weeks in group $1(93.3 \pm 4.0)$ and group 2 (92.3 \pm 5.5$)$ compared to the male control $(71.0 \pm 2.0)$ respectively. In contrast, the bicarbonate levels revealed a decrease that was insignificant in group $1(21.6 \pm 0.57)$ and group $2(22.6 \pm 0.57)$ compared to the male control (27.0 \pm 1.0$)$ after two weeks and a further insignificant decrease after four weeks in group $1(16.3 \pm 1.5)$ and group $2(16.6 \pm 1.52)$ in comparison to the male control $(27.0 \pm 1.0)$ respectively.

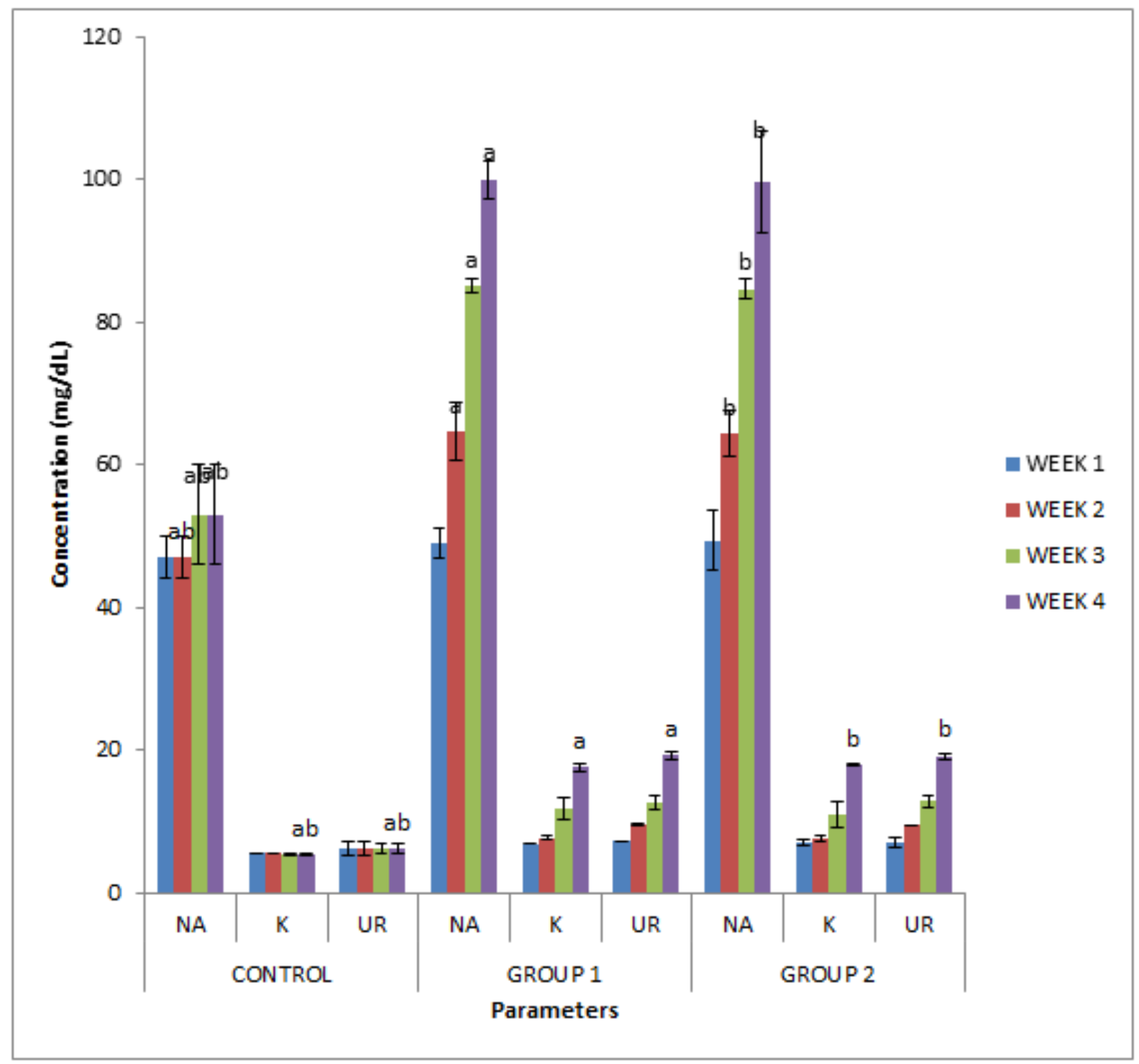

Data are mean \pm standard deviation of triplicate determinations. Superscripts $a, b$, indicate significant difference $(\mathrm{P}<0.05)$ when compared to the control group.

Superscript $\mathrm{A}^{(\mathrm{a})}$ denotes significant difference when the normal control group are compared with group 1.

Superscript $\mathrm{B}^{(\mathrm{b})}$ denotes significant difference when the normal control group is compared with group 2. Values without superscripts indicate no significant difference when the normal control is compared to group 1 and 2

Figure 5. Effects of chronic exposure to pesticides on some selected kidney markers of male rats 


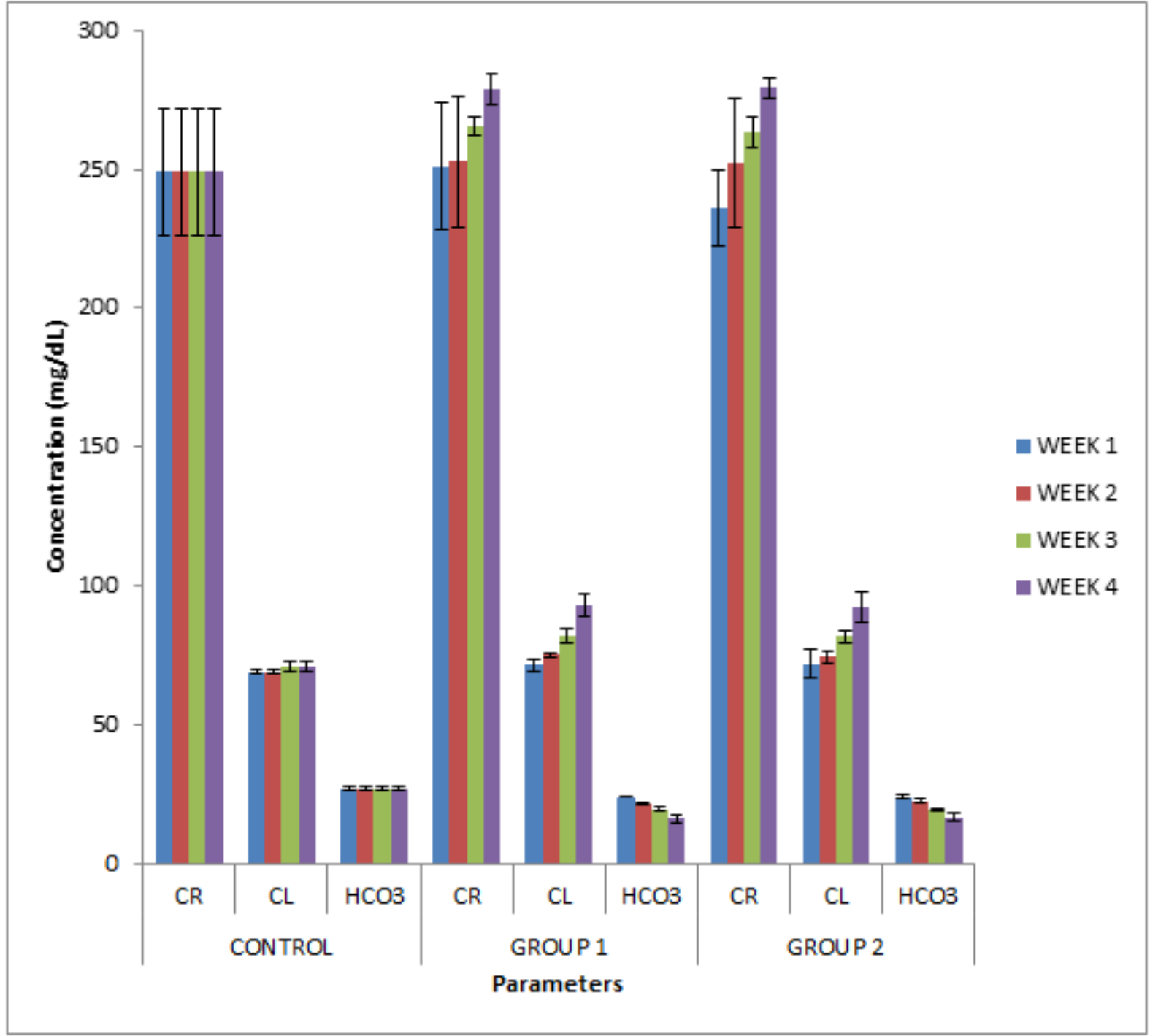

Data are mean \pm standard deviation of triplicate determinations. Superscripts $a, b$, indicate significant difference $(\mathrm{P}<0.05)$ when compared to the control group.

Superscript $\mathrm{A}^{(\mathrm{a})}$ denotes significant difference when the normal control group are compared with group 1.

Superscript $\mathrm{B}^{(\mathrm{b})}$ denotes significant difference when the normal control group is compared with group 2. Values without superscripts indicate no significant difference when the normal control is compared to group 1 and 2

Figure 6. Creatinine, chloride ion and bicarbonate concentration of male rats exposed to pesticides 


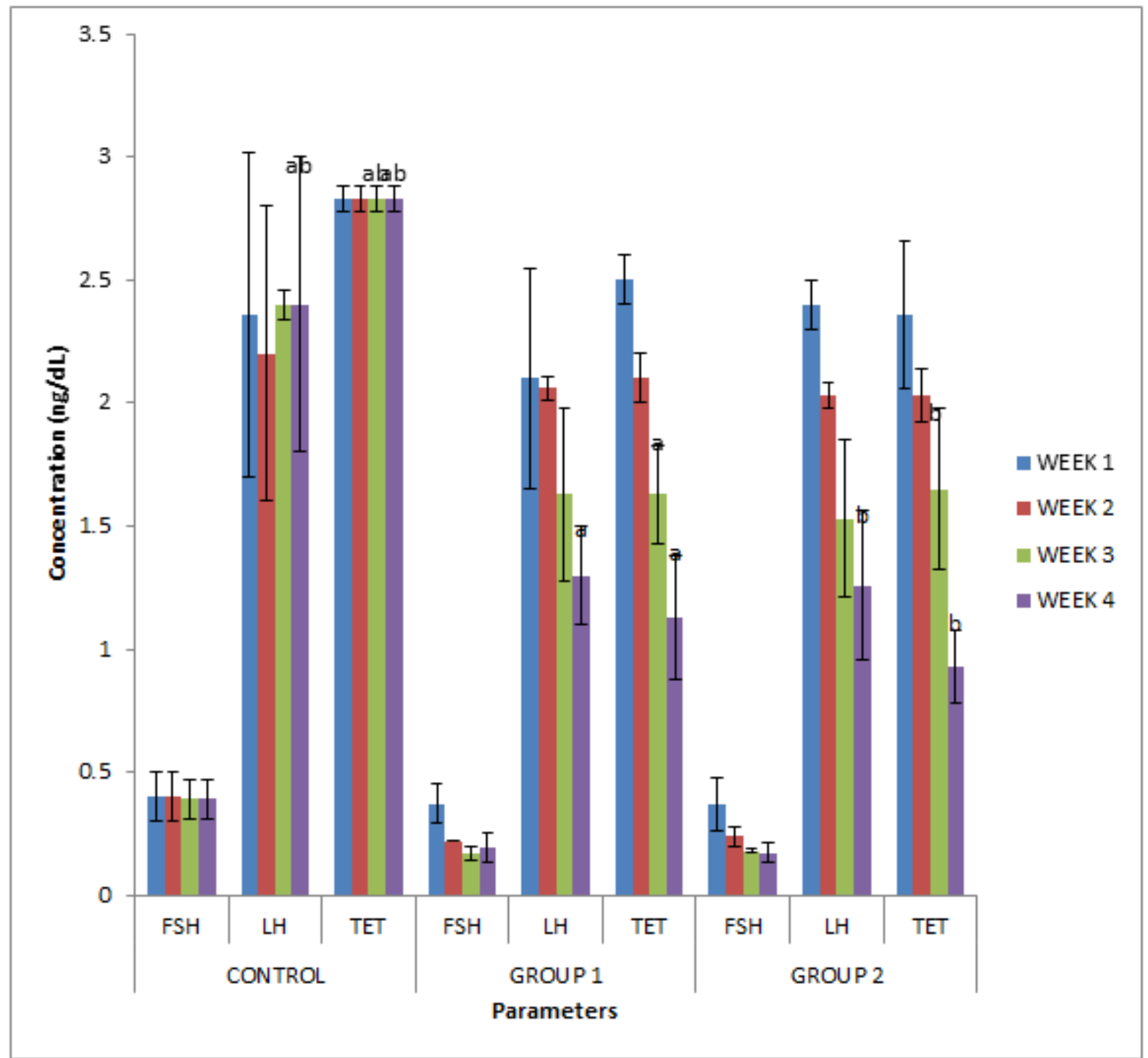

Data are mean \pm standard deviation of triplicate determinations. Superscripts $a, b$, indicate significant difference $(\mathrm{P}<0.05)$ when compared to the control group.

Superscript $\mathrm{A}^{(\mathrm{a})}$ denotes significant difference when the normal control group are compared with group 1.

Superscript $\mathrm{B}^{(\mathrm{b})}$ denotes significant difference when the normal control group is compared with group 2 . Values without superscripts indicate no significant difference when the normal control is compared to group 1 and 2

Figure 7. FSH, LH and TET activities of male rats exposed to pesticides

Follicle-stimulating hormone (FSH), Luteinizing hormone (LH) and Testosterone (TET) activities of male rats exposed to pesticides are presented in Figure 7. After two weeks there was an insignificant decrease in the level of follicle-stimulating hormone of the exposed animals in group $1(0.22 \pm 0.0)$ and group $2(0.24 \pm 0.04)$ compared to the male control $(0.40 \pm 0.10)$ and a further insignificant decrease was observed after four weeks in the group 1 $(0.19 \pm 0.06)$ and group $2(0.17 \pm 0.04)$ when compared to the male control $(0.39 \pm 0.08)$ respectively. While Luteinizing hormone concentration also decreased insignificantly after two weeks in group $1(2.06 \pm 0.05)$ and group $2(2.03 \pm 0.05)$ compared to the male control $(2.20 \pm 0.60)$ but decreased significantly after four weeks in group $1(1.30 \pm 0.20)$ and group $2(1.26 \pm 0.30)$ when compared to the male control
(2.40 \pm 0.60$)$ correspondingly. Moreover the testosterone levels also revealed a decrease that was insignificant after two weeks in group $1(2.10 \pm 0.10)$ and group $2(2.03 \pm 0.11)$ compared to the male control $(2.83 \pm 0.05)$ but a significant decrease was observed after four weeks in group 1 $(1.13 \pm 0.25)$ and group $2(0.93 \pm 0.15)$ when compared to the male control $(2.83 \pm 0.05)$ respectively.

\section{Discussion}

For the toxicity of any exogenous compound to be established, the integrity of haematological indices must be investigated because it plays an important role in assessing the toxicity of any compound; hence accumulation of any 
exogenous compound in excess in the erythrocytes is usually a pointer to a clinic-pathological condition. In hematoxicity assessment, decrease or increase in blood variables is indicative of suppression of red blood cell production and such assay is important in red blood cell risk assessment because changes in haematological system has a very high predictive value for human toxicity when the results revealed from the assay is extrapolated to man (9)

Packed cell volume (PCV \%) is a marker employed for the determination of red blood cell volume, according to ${ }^{(10)}$ the PCV values are vital in evaluating the impact of stress on the health of experimental animals and oxygen carrying capacity of the erythrocyte. Data from this study showed that after two weeks, there was a significant decrease in PCV $(p<0.05)$ in the male rats in group 1 and group 2 exposed to these pesticides as compared to the male control and a further significant decrease after four weeks as shown in (figure 1). By virtue of the fact that synergy exist among the blood markers in all vertebrates, haemoglobin counts directly correlates with RBC's count ${ }^{(11)}$ and other vertebrates including man has also been reported to possess this close correlation between blood parameters ${ }^{(12)}$. In the present study, these pesticides caused significant decrease in haemoglobin $(\mathrm{Hb})$ concentration in the male after four weeks of chronic exposure (figure 1). The $\mathrm{Hb}$ level in all the exposed rats decreased significantly after 4 weeks. However this is perhaps a tendency that the $\mathrm{Hb}$ level of rats exposed to these pesticides will have a more significant decrease if the exposure time is prolonged because the decrease in $\mathrm{Hb}$ level was duration dependent as shown in (figure 4). A low hemoglobin count may also result in anemia since synergy exists among these blood parameters. Also, the male and female rats exposed to these ten pesticides exhibited an insignificant decrease in the RBC after 2 weeks and a further insignificant decrease after 4 weeks in comparison to the normal control groups respectively (figure 1). Decrease in red blood cell has been implicated as one of the major causes of anemia. The results of this study is in consonance with the observed result in a previous study ${ }^{(13)}$ who studied the effects of organophosphates on hematological changes in adult mice and their result showed an insignificant decrease in $\mathrm{RBC}$, $\mathrm{PCV}$ and $\mathrm{Hb}$ levels. Reduction in the RBC level in the male rats exposed to these ten pesticides can be a useful biomarker of exposure to pesticides poisoning in human beings if this results are extrapolated to human. The increase of WBC's count (figure 2) may not be unconnected to the activation of the animal's immune system and defence mechanism.

Furthermore, one of the essential organs in the animal body is the liver because it is primarily the site of elimination and deactivation of certain toxic xenobiotics. The prevalent use of pesticides in Nigeria and most under-developed countries has led to numerous diseases and dysfunctions that are in consonance with the observed influences in our present study ${ }^{(14)}$. Results from this study indicated that incessant exposure to these ten pesticides significantly elevated the concentrations of liver marker enzymes namely AST, ALP and ALT in the male (figure 3) rats. AST and ALT are very sensitive markers that indicated either acute and/or chronic hepatocellular injury ${ }^{(15)}$. Hence elevated levels of these enzymes in the plasma are a reflection of the condition of hepatic function ${ }^{(16)}$. So the elevated concentration of ALT (figure 3) in the plasma is indicative of a likely hepatotoxicity. In the same way, ${ }^{(17)}$ observed that the elevation of ALT enzyme in the plasma is not unconnected to the fact that the enzyme leaked into the blood stream from the liver cytosol which is a reflection of liver dysfunction or damage. On the other hand, according to ${ }^{(18)}$ ALP is employed many a times for the assessment of the integrity of the plasma membrane, so on such premise, elevation of the tissue activity of ALP in our present study following the incessant exposure of these pesticides by inhalation may not be unconnected to liver plasma membrane distortion. Suffice to say that synthesis of plasma protein is one of the main functions of the liver. However, the results of this present study demonstrated a significant decrease in the levels of Total protein in the male rats after four weeks (figure 4) indicating a possible liver damage. According to (19) hypoproteinemia or reduction in total protein levels occurs as a result of liver damage since plasma protein is synthesized in the liver.

Data from our current study showed that incessant exposure of fumes of these pesticides by inhalation may not have interfered with the integrity of the kidney but revealed a possible toxicity if the exposure time is prolonged. Renal function markers such as creatinine, urea and plasma electrolytes are universally used to assess the functional capacity of the kidney of experimental animals, increased levels is indicative of a possible defective functional condition ${ }^{(20)}$. The observed increases in plasma potassium and sodium ions with a concomitant increase in chloride ion level after four weeks (figure 5 and 6) may be due to possible interference with renal function by the pesticides which may be attributed to the inability of the exposed animals to regulate an electrolyte balance. Furthermore, the increased concentration of urea in the plasma observed in this study is suggestive of possible renal impairment or increased rate of the catabolism of protein following exposure to high concentrations these pesticides. In addition, the observed insignificant increase in creatinine level further substantiates these findings. Studies (21) have demonstrated that plasma creatine concentration is a good marker of glomerular filtration rate. The elevation in creatinine levels may indicate possible changes in kidney function ${ }^{(22)}$. The elevated concentration of chloride ion observed in the experimental rats is not unanticipated because it has been reported that sodium retention is directly connected with chloride ion, since most sodium re-absorption is coupled with chloride ion re-absorption ${ }^{(23)}$. 
Furthermore, a large array of environmental factors influence the function and development of the reproductive system, pesticides, heavy metals, etc. and physical agents like heat and irradiation have been reported to affect steriodogenesis and spermatogenesis ${ }^{(24)}$. From this study, the effect of chronic exposure of fumes of these pesticides on reproductive hormones of male rats as shown in (figure 7) respectively connote that prolonged exposure of these toxicants to rats may possibly lead to reproductive toxicity and possibly interfere with the fertility profile of this animals, since data from this study reveal that the levels of Follicle Stimulating Hormone and Testosterone decreased insignificantly after 2 weeks and exhibited a further significant decrease after 4weeks while the levels of Luteinizing hormone decreased insignificantly after 4 weeks (figure 7). These findings are suggestive of the fact that prolonged exposure to the fumes of these pesticides may likely interfere with the reproductive profile of the animals on continuous exposure since the decrease was duration dependent.

\section{Conclusions}

From this research carried out, it can be concluded that data from the current study suggest that chronic exposure to different kinds of pesticides by inhalation can cause adverse effects on biochemical parameters and subsequent damage to various organs such as liver and kidney perhaps, through the generation of reactive oxygen species. So minimal exposure to these pesticides should be encouraged and perhaps use of safety wears to minimize exposure, if the outcome of this research can be extrapolated to man.

\section{Acknowledgements}

The authors received no external funding for this study.

\section{Conflict of Interest}

The authors declare that there is no conflict of interests regarding this article.

\section{REFERENCES}

[1] Czarniewska, E., Kasprzyk, A., and Ziemnicki, K. (2003). Effect of paraquat and metoxychlor on antioxidant enzymes in frog Rana esculenta L. liver. Biological Letters, 40 (2) : 125-133.

[2] Konradsen, F., van der Hoek, W., Cole, D. C., Hutchinson, G., Daisley, H., Singh, S., and Eddleston, M. (2003). Reducing acute poisoning in developing countries - options for restricting the availability of pesticides. Toxicology, 192(2), 249-261
[3] Committee on Toxicity of Chemicals. (2002). Risk Assessment of Mixtures of Pesticides and Similar Substances.

[4] British Colombia. (2013). Human PesticideExposure. http://www.agf.gov.bc.ca/pesticides/k_2.htm (lastaccessed in 10 Apr. 2013). Butyryl cholinesterase andacetylcholinesterase by the organophosphate chlorpyrifos oxon. Toxicology and Applied Pharmacoloogy, 241:135-142.

[5] Kemabonta, K. A., and Akinhanmi, F.O. (2013). Toxicological Effects of Chlorpyrifos, Dichlorvos and Alpha Cypermethrin onAdult Albino Mice, Mus musculus. PAT December, 9 (2): 1-17, ISSN: 0794-5213.

[6] Mansour, S. A. (2004). Pesticide exposure- Egyptian scene. Toxicology, 198:91-115.

[7] Wan, S. X., Zhang, J. H., and Wang, J.D. (2006).Fluoride-induced changes inthe expression of epidermal growth factorand its receptor in testicular tissues ofyoung male rats. Research Report on Fluoride,39(2): $121-125$.

[8] Chedrese, P. J., Piasek, M., and Henson, M. C. (2006). Cadmium as an endocrine disruptor in the reproductive system. Immunology, Endocrine \& Metabolic Agents in Medicinal Chemistry (Formerly Current Medicinal Chemist ry-Immunology, Endocrine and Metabolic Agents), 6(1): 27-35.

[9] Olson, H., Betton, G., Robinson, D., Thomas, K., Monro, A., Kolaja, G., and Dorato, M. (2000). Concordance of the toxicity of pharmaceuticals in humans and in animals. Regulatory Toxicology and Pharmacology, 32(1): 56-67.

[10] Larson, K., Sahm, J., Shenkar, R., \& Strauss, B. (1985). Methylation-induced blocks to in vitro DNA replication. Mutation Research/Fundamental and Molecular Mechanisms of Mutagenesis, 150(1-2): 77-84.

[11] El-Bakary, A. S., Abdel-Gawad, A. F., El-Mofty, M. M., and Attia, S. I. (1995). Effect of dimethoate on some haematological parameters of toad Bufo regularis. Journal of King Saud University - Agricultural Sciences, 1: 85-93.

[12] Harris, C. R., and Svec, H. J. (1976). Onion maggot resistance to insecticides. Journal of Economic Entomology, 69(5): 617-620.

[13] Ambali, S. F., Ayo, J. O., Esievo, K. A., and Ojo, S. A. (2011). Hemotoxicity induced by chronic chlorpyrifos exposure in Wistar rats: mitigating effect of vitamin C. Veterinary medicine international, 20 (11): 112-113.

[14] Otitoju, O., and Onwurah, I. N. E. (2005). Superoxide dismutase (SOD) activity and serum calcium level in rats exposed to a locally produced insecticide "Rambo Insect Powder”. Animal Research International, 2(1): 261-266.

[15] Barth, P. T. (1979). RP4 and R300B as wide host-range plasmid cloning vehicles. Plasmids of medical, environmental and commercial importance, 1: 399-410.

[16] Konan, N. A., Bacchi, E. M., Lincopan, N., Varela, S. D., and Varanda, E. A. (2007). Acute, subacute toxicity and genotoxic effect of a hydroethanolic extract of the cashew (Anacardium occidentale L.). Journal of ethnopharmacolog y, 110(1): 30-38. 
[17] Shakoori, A. R., Butt, U., Riffat, R., and Aziz, F. (1994) Haematological and biochemical effects of danitol administered for two months in the blood and liver of rabbits. Zeitschrift Fur Angewandte Zoologie, 80: 165-165.

[18] Akanji, M. A., Olagoke, O. A., and Oloyede, O. B. (1993). Effect of chronic consumption of metabisulphite on the integrity of the rat kidney cellular system. Toxicology, 81(3): 173-179.

[19] Anita, A., Maya, S., Deepa, N., Chennazhi, K. P., Nair, S. V., and Jayakumar, R. (2012). Curcumin-loaded N, O-carboxymethyl chitosan nanoparticles for cancer drug delivery. Journal of Biomaterials Science, Polymer Edition, 23(11): 1381-1400.

[20] Yakubu, M. T., Bilbis, L. S., Lawal, M.,and Akanji, M. A. (2003). Evaluation of selected parameters of rat liver and kidney function following repeated administration of yohimbine. Biokemistri, 15(2): 50-56.

[21] Khalil, R. A., and Granger, J. P. (2002). Vascular mechanisms of increased arterial pressure in preeclampsia: lessons from animal models. American Journal of Physiology-Regulatory, Integrative and Comparative Physiology, 283(1): 29-45.

[22] Soliman, A. T., ElZalabany, M. M., Salama, M., and Ansari, B. M. (2000). Serum leptin concentrations during severe protein-energy malnutrition: correlation with growth parameters and endocrine function. Metabolism, 49(7): 819-825.

[23] Browse, J. (2005). Jasmonate: an oxylipin signal with many roles in plants. Vitamins \& Hormones, 72: 431-456.

[24] Vermeulen, H (1994). Enzyme activities and histopathology of selected tissues in rats treated with potassium bromate. African Journal of Biomedical Research, 11(1): 45-46. 